\title{
Internet for English Teaching
}

Gogilashvili Mariami

Georgian National University (SEU),Tbilisi

https://doi.org/10.52340/idw.2021.538

\begin{abstract}
The advance of technology has made the emergence of the Internet become more and more important in language teaching and learning. For this reason, this paper addresses its discussion on the importance of the Internet use in English language teaching. this current study aims at describing how Lessons in English online can solve a number of didactic tasks: develop reading skills and abilities, using global networking materials; Improve students' writing skills; Complete students' vocabulary; Develop students' motivation to learn English.
\end{abstract}

Key words: language teaching, internet, current study, global network, skills.

\section{Introdaction}

Use of technology is not new in language teaching not to mention in the teaching of English. Tape recorders, language laboratories and video have been widely used in practice of English language teaching since the 1960s. In the early 1980s the use of technology in the practice of English language teaching has been improved in term of using the computer-based materials for language teaching, often referred as CALL (Computer Assisted Language Learning). in the 1990s the use of technology in the practice of English Language teaching embraced to the use of internet and web-based tools that the term TELL (Technology Enhanced Language Learning) appeared (Dudeney \&Hockly,2007: 7). The rapid development of the internet in the 1990s has had a wide impact on the teaching and learning of English. (Lee, Jor and Lai, 2005: vii).

We are in 21 st century, a period full of advancement with technologies. The wide range of technologies is ubiquitous in language learning. I would like to bring out that the English teacher would face failure in the classroom, if he/she is not updating the latest technological innovations. The English teachers should change the method of instruction by integrating the technologies in their teaching. Tech-savvy teachers can incorporate Computer Assisted Language Learning (CALL) in teaching methodology. The innovative tools that should be integrated with the curriculum through technologies in teaching English are Blogs, Podcasts, Wikis, Google Docs, Good Reads, Mixed Ink, eBooks, Edmodo, etc Most teachers believe that they may get much benefit through the use of internet. They can use it as one way of getting resources for conducting their teaching. They can use it as a medium to exchange information related to their teaching. Warschauer, Shetzer and Meloni (2002: 7) propose five main reasons to use the Internet for English teaching called "ALIVE". They believe that internet provides a lowcost method of making language learning meaningful, it also represents important new forms of literacy needed in the 21 st century.

The main goal of foreign language teaching is to form and develop a communication culture of studants to teach practical knowledge of a foreign language. 
The teacher's task is to activate the student's cognitive activity in the process of learning a foreign language. Modern pedagogical technologies such as collaborative learning, project methodology, use of new information technologies, Internet resources help to implement a person-centered approach to learning, individualization and differentiation of learning, taking into account the capabilities of children, the level of learning. Forms of working with computer training programs in foreign language lessons include: teaching vocabulary; Pronunciation practitioner; Teaching dialogue and monologue; Teaching writing; Develop grammatical phenomena. Today, new methods of using Internet resources oppose the teaching of traditional foreign languages. Teaching communication in a foreign language requires the creation of real, real-world situations (the so-called principle of authenticity of communication), which will facilitate the study of the material and develop adequate behavior. New technologies, in particular the Internet, are trying to correct the error.

One of the main requirements for learning foreign languages using Internet resources is to create interaction in the lesson, which is commonly referred to as interactivity in methodology. Interactivity is "combining, coordinating, and complementing the efforts of a communicative goal through speech." By teaching the true language, the Internet promotes the development of speech skills, as well as the teaching of vocabulary and grammar, ensuring genuine interest and, consequently, effectiveness. Interactivity not only creates real situations, but also forces students to respond adequately to them through a foreign language.

\section{Main Body}

Lessons in English online can solve a number of didactic tasks: develop reading skills and abilities, using global networking materials; Improve students' writing skills; Complete students' vocabulary; Develop students' motivation to learn English. In addition, the work aims to explore the possibilities of Internet technologies to broaden the horizons of children, to establish and maintain business relationships and contacts established in English-speaking countries. The ultimate goal of foreign language teaching is the teaching of free orientation in a foreign language environment and the ability to respond adequately in a variety of situations.

One of the technologies that provides student-centered learning is the project method as a way to develop creativity, cognitive activity and independence. The typology of projects is diverse. According to M.E.Breigina, projects can be divided into monoprojects, collective, oral, specific, written and internet projects. Although in real practice mixed projects are often solved, in which there are signs of research, creative, practiceoriented and informative. Project work is a multi-layered approach to language learning that includes reading, listening, speaking, and grammar. The project method encourages students to develop active independent thinking and leads them to collaborative research work. In my opinion, project-based learning is important in that it teaches children to collaborate, and teaching collaboration enhances moral values such as mutual aid and empathy, creates creativity, and activates students. In general, the training process of the project is inseparable from training and education. I always use the project method as a way to develop creativity, cognitive activity and independence in my lectures. There are two or three students in this work. Students help each other, also work seperatly, and have opportunity to search a lot of information. They like such activites and always do their best to achive their goals. Live communication was indispensable in traditional teaching Between teacher and students, a black, white board is handy there were tools while the teacher was leading the lesson In the process, the digital revolution even turned 
educational upside down Space, competing with traditional teaching, teacher imposed It became a facilitator, a wayfarer, and a lesson process. For the first half of the 19th century, one in Great Britain. The teacher sent the study mass to his students by mail-Lebs and taught them while at university for the first distance learning Owned by the University of London.

In 1858 the University of London was founded with a distance teaching. By the end of the twentieth century distance learning was improving, however distribution to the masses became possible only when access to the Internet and computers is essential for learning. The internet has spread, distance learning envisages three basic forms of learning These are: computer training, distance learning online and mobile learning (mlearning). Various platforms in online learning offer virtual classrooms, such as: zoom, moodle, microsoft teams. Online. Distinguish between asynchronous, synchronous and mixed teaching methods of online teaching. The synchronous teaching method includes a traditional teaching analogy where all students lead the lesson process with the teacher for a limited amount of time. Synchronous training Includes: Chat, Messenger, Video Audio Conferencing, Apps Shared sharing, virtual board and opinion polling on the internet with the help of Asynchronous training is not limited in time, for himtypical forms are wiki, blogs, forums, blogs and more communication networks. Mixed learning includes independent and Teacher-dependent teaching. Work directly in the audience or Web seminar or webinar. Necessary as a result of the spread of Covid-19 in Georgia in 2020 Became secondary schools and higher education institutions Switch to online tutoring, which has replaced the traditional classroom and Showed the public the need for distance learning, in which the role of the internet is unclear. Educational introduction of innovations, in the modern era, the level of teaching more made it a priority. All over the world, especially in the learning process It is a very important fact to increase students' motivation, digitally the use of educational resources plays an important role at this time Performs. Properly selected learning resources for lesson effectiveness, It is a precondition for improving the quality and raising the quality of teaching. The teacher needs to avoid certain stages of teaching, the standard framework of the manual, make a free choice. To create a different style convenient for teaching, to create training resource and introduce innovation.

In the era of globalisation, like today, due to the advance of technology, the emegence of Internet cannot be denied and ignored in English language teaching. In other words, the Internet has become very important in English language classroom. Estman (1996:34) describes it that the web with its ease of use and accessibility will continue to grow in the importance of English language teaching. In addition, Warschauer (2000) present the list of five reasons to use the Internet for teaching as mentioned in the followings:

(a) it provides authentic language materials;

(b) it enhances the student's level of literacy in conducting on-line communication;

(c) it enables the student to interact with native and nonnative speakers for 24 hours on end;

(d) it makes the learning process lively, dynamic, and interesting;

(e) it gives both the student and the teacher the power to work efficiently.

most of Internet for English Teaching deals with how to use the Internet to teach English. The authors describe ways in which the Internet can be used for various types of teaching activities, including collaborative assignments, student research, and studentmanaged publishing of their work. Throughout this discussion very practical techniques 
are given, along with examples of assignments and reminders that any use of the technology must be grounded in pedagogical theory and deliberate implementation that reflects theory and proven practice. The authors also discuss distance education, mostly describing various online courses or programs, but also identifying issues relevant to developing and evaluating distance courses or programs.

\section{Conclusion}

The use of internet in the practice of English language teaching is unavoidable. In general, the use of internet in English Language teaching contexts provides many benefits both for teachers and students as Lee, Jor and Lei (2005: 4) claim that innovative uses of technology for education such as the Internet and Web-based instruction are a recent intellectual development in education. In particular, teachers need to consider the use of the Internet and be familiar to use it in their daily lives not only to support their teaching but also to enhance and improve their own knowledge. It is through the use of the Internet that they can get abundant resources for their teaching as well as to get in touch with other teachers from other places, get recent developments and current issues of the English language teaching by joining some international professional organizations. The greatest strength of Internet for English Teaching is its highly practical approach to describing and explaining uses of the Internet for language tea in the present day the progress in the field of education is due to development of web assisted language learning. It facilitates the learners with innovative gears for teaching and also helps the learners to help to spread the knowledge faster to the world. The development of computer and internet has affected teaching positively.

So from the above study it can be concluded that the internet being the most available, flexible, practical way and a treasure of vast knowledge, can be utilised for the purpose of developing good communication skills. A teacher and learner can better utilize it by the application and sharing of real-life experiences and situations within a healthy learning environment. So it is advisable to take internet and use of technology as it allows for a great number of opportunities to communicate in the target language.

\section{Bibliography:}

1. Crystal, David. 2006. Language and the Internet Second Edition. Cambridge: Cambridge University Press.

2. Dudeney, Gavin and Nicky Hockly. 2007. How to Teach English with Technology. Edinburgh Gate Harlow Essex: Pearson Education Limited.

3. Lee, Cynthia, George Jor and Eva Lai. 2005. W eb-based Teaching and English Language Teaching: Hong Kong: The Chinese University Press.

5. http://www.teachingenglish.org.uk/

6.https://www.researchgate.net/publication/220374140_How to teach_English_with_Techn ology: 


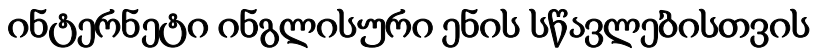

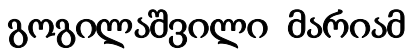

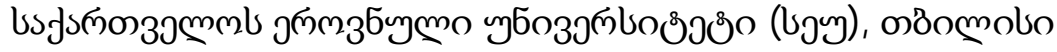

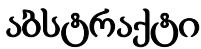

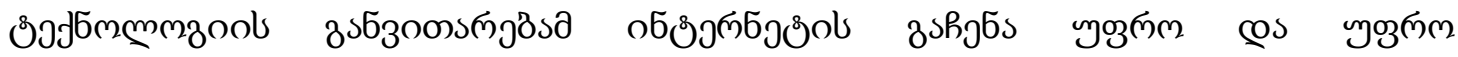

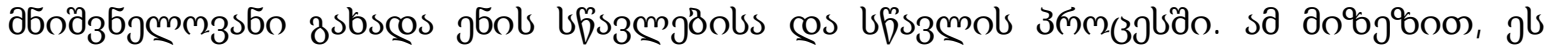

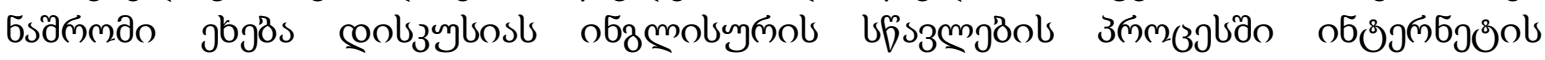

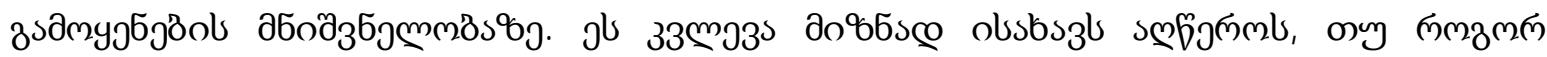

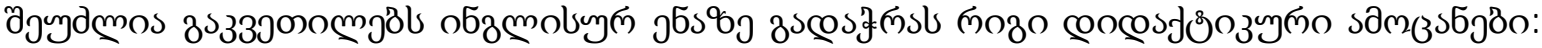

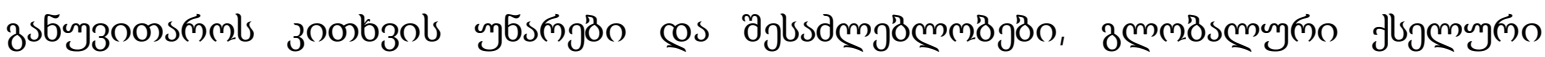

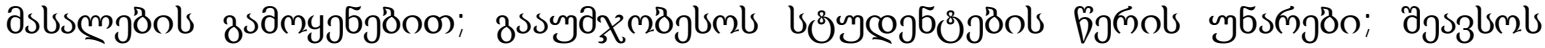

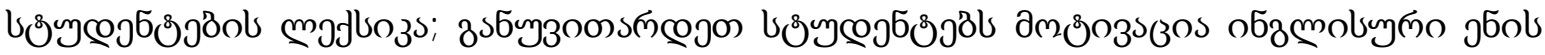
gjlstbissmsce.

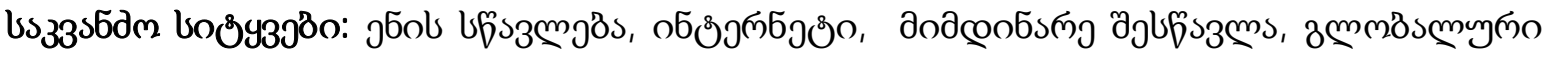

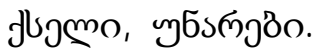

